\title{
HIPERTENSI PADA KEHAMILAN DAN KEJADIAN BBLR DI RSUD KOTA TASIKMALAYA
}

\author{
Lia Herliana \\ Poltekkes Kemenkes Tasikmalaya \\ liaherliana3@gmail.com
}

\begin{abstract}
ABSTRAK
Bayi BBLR yang seringkali menjadikan berisiko tidak saja karena komplikasi neonatal yang dialami (misal hiperbilirubinemia dan sindrom gawat nafas) tetapi juga oleh faktor resiko lainnya (misal anomali bawaan yang dikaitkan dengan BBLR). BBLR memerlukan penatalaksanaan yang tepat oleh seorang perawat karena apabila tidak mendapatkan perawatan yang adekuat, BBLR akan menimbulkan dampak terhadap sistem pernafasan, sistem penglihatan, refleks, gerakan-gerakan motorik bahkan dampak jangka panjang yaitu kesulitan belajar dan tingkah laku (neurobehaviour). Penelitian dilatarbelakangi oleh tingginya angka kejadian BBLR di RSUD Kota Tasikmalaya pada setiap tahunnya sehingga diperlukan adanya penelusuran dari penyebab kejadian BBLR yang dialami. Tujuan penelitian untuk mengetahui adanya hubungan antara hipertensi pada kehamilan dengan kejadian BBLR di RSUD Dr. Soekardjo Kota Tasikmalaya. Hipotesis penelitian ada hubungan antara hipertensi pada kehamilan dengan kejadian BBLR. Manfaat penelitian memberikan dasar praktek berbasis bukti ilmiah (evidences based practice) kepada praktisi keperawatan, bahwa ada hubungan antara hipertensi pada kehamilan dengan kejadian BBLR. Metode penelitian kuantitatif dengan pendekatan cross sectional. Pengolahan data menggunakan analisis univariat dan bivariat. Hasil penelitian tidak ada hubungan yang signifikan antara hipertensi pada kehamilan dengan kejadian BBLR di RSUD Kota Tasikmalaya dengan $p$ value $>0,05$. Saran hendaknya perawat lebih meningkatkan pendidikan kesehatan pada masyarakat agar masyarakat lebih memahami tentang resiko terjadinya BBLR.

Kata kunci:hipertensi pada kehamilan, BBLR
\end{abstract}

\section{ABSTRACT}

$L B W$ babies often make it risky not only because of neonatal complications experienced (eg hyperbilirubinemia and respiratory distress syndrome) but also by other risk factors (eg congenital anomalies associated with $L B W$ ). $L B W$ requires proper management by a nurse because if it does not get adequate care, $L B W$ will have an impact on the respiratory system, vision system, reflexes, motor movements and even long-term effects of learning difficulties and behavior (neurobehavior). This research is motivated by the high incidence of $L B W$ in Tasikmalaya City Hospital in each year so that it is necessary to trace the causes of $L B W$ events experienced. The aim of the study was to determine the relationship between hypertension in pregnancy and the incidence of $L B W$ in $D r$. Soekardjo, Tasikmalaya City. The research hypothesis has a relationship between hypertension in pregnancy and the incidence of $L B W$. The benefits of research provide a basis for evidence-based practice to nursing practitioners, that there is a relationship between hypertension in pregnancy and the incidence of LBW. Quantitative research method with approach cross sectional. Processing data using univariate and bivariate analysis. The results of the study there was no significant relationship between hypertension in pregnancy with the incidence of $L B W$ in Tasikmalaya City Hospital with p value> 0.05. Suggestions should nurses further improve health education in the community so that people better understand the risks of $L B W$.

Keywords: hypertension in pregnancy, $L B W$

PENDAHULUAN

Bayi berat lahir rendah (BBLR) merupakan permasalahan serius yang dihadapi oleh dunia. Di Indonesia kejadian
BBLR bervariasi secara nasional. Menurut SDKI 2002-2003 kejadian BBLR sebesar $6 \%$. Kejadian BBLR berdasarkan provinsi 
bervariasi dengan rentang $2 \%-15,1 \%$. Di Jawa Barat BBLR merupakan penyebab kematian bayi (usia 0-1 tahun) nomor 3 pada tahun $1998(8,5 \%)$ dan nomor 4 pada tahun 1999 (8,71\%). BBLR seringkali menjadikan bayi beresiko tidak saja karena komplikasi neonatal yang dialami (misal hiperbilirubinemia dan sindrom gawat nafas) tetapi juga oleh faktor resiko lainnya (misal anomali bawaan yang dikaitkan dengan BBLR). BBLR memerlukan penatalaksanaan yang tepat oleh seorang perawat karena apabila tidak mendapatkan perawatan yang adekuat, BBLR akan menimbulkan dampak terhadap sistem pernafasan, sistem penglihatan, refleks, gerakan-gerakan motorik bahkan dampak jangka panjang yaitu kesulitan belajar dan tingkah laku (neurobehaviour) (Montes \& Hoffman, 2004). Beberapa penelitian telah dilakukan yang berkaitan dengan dampak BBLR terhadap anak dalam tahap pertumbuhan dan perkembangan berikutnya. Vohr et al (2000) melakukan penelitian prospektif terhadap bayi-bayi prematur tentang faktor-faktor yang mempengaruhi perkembangan neurologi dan hasil fungsional pada anak usia sekolah dimana didapatkan hasil bahwa anak dengan riwayat prematur yang disertai dengan intraventrikular haemoragik (IVH) memiliki frekuensi lebih banyak untuk terjadinya serebral palsy, gangguan pendengaran, skore rendah terhadap perawatan diri sehari-hari, IQ yang rendah, kosa kata, membaca dan penghitungan matematik. Faktor lain yang mempengaruhi adalah faktor biologik, lingkungan sosial, pengetahuan ibu serta bahasa percakapan sehari-hari yang digunakan di rumah juga memberikan kontribusi terhadap pencapaian hasil optimal pada anak usia sekolah. Penelitian lain yang juga meneliti tentang pencapaian tingkat kognitif bagi anak sekolah adalah Hack et al (2003) dimana menyatakan bahwa bayi berat lahir rendah dan prematuritas serta ukuran kepala yang abnormal berdampak pada kemampuan kognitif, neurofungsional dan pengaturan fisik anak pada saat usia sekolah. Lain halnya dengan Saigal (2002) yang menyatakan bahwa tidak ada hubungan yang signifikan antara remaja dengan riwayat prematur dan remaja yang dilahirkan cukup bulan dalam hal harga diri (self esteem).

Bayi yang dilahirkan prematur dan berat badan rendah sangat beresiko untuk terjadinya gangguan mental dan perkembangan motorik terutama pada bayi yang dirawat di NICU (Datar, \& Jacknowitz, 2009). Pada umumnya, bayi prematur dan berat badan lahir sangat rendah juga memiliki insiden yang tinggi untuk terjadinya keterlambatan mental dan kondisi kecacatan. Diperkirakan setengah dari bayi berat lahir sangat rendah $(\mathrm{BB}<1500$ gr $)$ mengalami resiko kerusakan SSP (susunan syaraf pusat) akibat perdarahan intraventrikular yang juga menimbulkan resiko peningkatan kejadian kecacatan atau disabilitas (Resnick, Davis, \& Nelson, et al, 1987). 
Insidens prematuritas dan BBLR paling rendah pada kelas ekonomi menengah ke atas, karena wanita hamil pada kelompok tersebut biasanya dalam kondisi kesehatan yang baik, cukup gizi dan mendapat asuhan prenatal awal dan komprehensif. Insidens tertinggi terjadi pada kelas sosial ekonomi rendah dengan kombinasi keadaan yang buruk. Faktor lain seperti kehamilan multiple, hipertensi akibat kehamilan dan masalah plasenta yang menganggu perjalanan normal gestasi sebelum perkembangan fetal selesai, berperan terhadap sebagian besar kelahiran prematur dan BBLR (Hockenberry \& Wilson, 2009). Sulit untuk menentukan secara pasti penyebab dari BBLR, tetapi ada beberapa faktor resiko yang erat kaitannya dengan kejadian BBLR, yaitu umur ibu saat melahirkan, usia kehamilan saat melahirkan, tingkat pendidikan ibu dan jenis kelamin bayi yang dilahirkan.

Dari hasil-hasil penelitian yang telah dilakukan dapat dilihat bahwa kelahiran prematur dan BBLR sangat berpengaruh terhadap perkembangan anak di kemudian hari, untuk itu diperlukan upaya-upaya yang sifatnya promotif untuk mencegah dan meminimalisir kejadian prematuritas dan BBLR agar anak sebagai investasi bangsa di masa depan dapat lebih berkualitas dengan melakukan analisis terhadap faktor-faktor apa saja yang mempengaruhi kejadian BBLR di RSUD Kota Tasikmalaya.

Hasil studi pendahuluan di RSUD Kota Tasikmalaya didapatkan angka kejadian
BBLR pada tahun 2012 adalah 783 dari 4672 kelahiran atau sekitar $16,76 \%$. Dilihat dari angka tersebut jelas bahwa kejadian BBLR di RSUD Kota Tasikmalaya masih terhitung besar, maka perlu kiranya memperhatikan faktor-faktor apa saja yang mempengaruhi kejadian BBLR tersebut.

\section{BAHAN DAN METODE}

Jenis dan rancangan penelitian yang digunakan adalah kuantitatif dengan pendekatan cross sectional, dimana pengukuran variabel-variabelnya dilakukan hanya satu kali. Populasi penelitian adalah semua ibu yang memiliki bayi dan dirawat di RSUD Kota Tasikmalaya dengan sampel penelitian adalah ibu yang memiliki bayi yang dirawat di Ruang Perinatologi, NICU dan Ponek RSUD Kota Tasikmalaya pada periode bulan September s.d. Desember 2015. Teknik pengambilan sampel accidental sampling, dengan criteria inklusi: 1) Ibu yang memiliki bayi yang dirawat di Ruang Perinatologi, NICU dan Ponek RSUD Dr. Soekardjo Kota Tasikmalaya baik yang lahir dengan BBLR atau tidak, 2) Usia kehamilan pada saat dilahirkan pada kisaran $36-42$ minggu (aterm), 3) Kondisi bayi dan ibu sehat, 4) Ibu bisa tulis dan baca serta 5) Ibu melahirkan di RSUD Kota Tasikmalaya atau di luar RSUD Kota Tasikmalaya. Pengumpulan data dilakukan dengan kuesioner yang berisi 16 pertanyaan yang berkaitan dengan faktor demografi ibu (biodata, data bayi yang dilahirkan, data sosial ekonomi, data lingkungan rumah dan fasilitas kesehatan). 
HASIL

Penelitian ini dilaksanakan mulai tanggal 29 September sampai dengan 27 Oktober 2015 terhadap 65 responden.

a. Karakteristik responden berdasarkan usia

Tabel 1 Distribusi Responden Menurut Usia

\begin{tabular}{lcc}
\hline Usia Ibu & Jumlah & Prosentase \\
\hline$<20$ tahun & 6 & 9,2 \\
$20-35$ tahun & 48 & 71,6 \\
$>35$ tahun & 11 & 16,4 \\
\hline Jumlah & $\mathbf{6 5}$ & $\mathbf{1 0 0}$ \\
\hline
\end{tabular}

Tabel 1 memperlihatkan bahwa responden yang melahirkan di RSUD

Dr. Soekardjo terbanyak ada pada rentang usia 20 - 35 tahun yaitu sebanyak 48 orang $(71,6 \%)$.

b. Karakteristik kelahiran bayi

Tabel 2. Distribusi kelahiran bayi berdasarkan berat-badan

\begin{tabular}{lcc}
\hline Kejadian BBLR & Jumlah & Prosentase \\
\hline BBLR & 22 & 33,8 \\
Tidak BBLR & 43 & 66,2 \\
\hline Jumlah & $\mathbf{6 5}$ & $\mathbf{1 0 0}$ \\
\hline
\end{tabular}

Dari tabel 2.di atas dapat dilihat bahwa ternyata sebagian responden tidak mengalami kejadian BBLR yaitu sebanyak $66,2 \%$, sedangkan $33,8 \%$ mengalami BBLR.

c. Distribusi kejadian hipertensi kehamilan Tabel 3. Distribusi responden berdasarkan hipertensi pada kehamilan

\begin{tabular}{ccl}
\hline $\begin{array}{c}\text { Hipertensi pada } \\
\text { kehamilan }\end{array}$ & Jumlah & Prosentase \\
\hline Ya & 15 & 23,1 \\
Tidak & 50 & 76,9 \\
\hline Jumlah & $\mathbf{6 5}$ & $\mathbf{1 0 0}$ \\
\hline
\end{tabular}

Pada tabel 3 di atas dapat dilihat bahwa sebagian besar responden tidak mengalami hipertensi pada masa kehamilan yaitu sebesar $76,9 \%$ dan sebagian lagi yaitu sebanyak 23,1\% mengalami hipertensi.

d. Tabel silang hubungan antara masalah plasenta dan kehamilan dengan kelahiran BBLR

Dalam penelitian ini analisis bivariat dilakukan untuk mengetahui gambaran hubungan antara variabel independent yaitu faktor-faktor yang berhubungan dengan kejadian BBLR dan variabel dependent yaitu kejadian BBLR

Tabel 4. Tabel silang antara hipertensi pada kehamilan dengan kejadian BBLR

\begin{tabular}{|c|c|c|c|c|c|c|c|}
\hline \multirow{3}{*}{ Variabel } & \multicolumn{4}{|c|}{ Kejadian BBLR } & \multirow{3}{*}{ P value } & \multirow{3}{*}{ OR } & \multirow{3}{*}{ 95\% CI } \\
\hline & \multicolumn{2}{|c|}{ BBLR } & \multicolumn{2}{|c|}{ Tidak BBLR } & & & \\
\hline & & $\%$ & & $\%$ & & & \\
\hline \multicolumn{5}{|c|}{ Hipertensi kehamilan } & \multirow{4}{*}{0,792} & \multirow{4}{*}{1,417} & \multirow{4}{*}{$0,430-4,665$} \\
\hline a. Ya & 6 & 27,3 & 9 & 23,1 & & & \\
\hline b. Tidak & 16 & 72,7 & 34 & 76,9 & & & \\
\hline Jumlah & 22 & 100 & 43 & 100 & & & \\
\hline
\end{tabular}


Tabel 4 memperlihatkan bahwa pada ibu yang mengalami hipertensi kehamilan, 27,3\% melahirkan anak BBLR sedangkan pada ibu yang tidak mengalami hipertensi pada kehamlan sekitar 72,7\% melahirkan anak dengan BBLR. Hasil pengujian statistic diperoleh $\mathrm{p}$ value $=0,792$ artinya bahwa tidak ada hubungan yang signifikan antara hipertensi pada kehamilan dengan kejadian BBLR pada bayi yang dilahirkan.

\section{PEMBAHASAN}

Hipertensi adalah komplikasi yang sering terjadi pada ibu hamil. Pada ibu hamil dengan hipertensi, pembuluh darah mengalami penyempitan, begitu pula pembuluh darah di plasenta sehingga menyebabkan pasokan oksigen dan nutrisi untuk janin kurang. Jika hal tersebut dibiarkan terus menerus dapat menyebabkan lahirnya bayi berat badan lahir rendah (BBLR), kelahiran prematur, dan kematian janin. BBLR memiliki resiko kematian lebih tinggi dibandingkan dengan bayi yang lahir dengan berat normal karena BBLR sangat rentan terpapar penyakit, terkena asfiksia, hipotermi dan infeksi (Sigmawati, 2010). Hipertensi pada saat hamil akan berdampak pada ibu dan janin. Dengan tingginya tekanan darah maka arus darah akan mengalami gangguan begitu pula pada organ ginjal, hati, otak, rahim dan juga plasenta.Ibu hamil yang menderita preeklampsia akan berdampak pada janin dimana nutrisi dan oksigen akan mengalami kondisi abnormal. Hal ini disebabkan karena pembuluh darah akan mengalami penyempitan. Pada kondisi ibu hamil yang mengalami preeklamsia maka tumbuh kembang janin akan terhambat sehingga menyebabkan bayi lahir dengan berat badan yang rendah. Bahkan dapat meningkatkan risiko terjadinya kelahiran prematur.Sedangkan pada kasus preeklamsia yang berat maka bayi harus segera dilahirkan, kondisi ini disesuaikan dengan janin yang sudah dapat hidup diluar rahim atau tidak.Diperlukan pemeriksaan lebih lanjut oleh dokter kandungan untuk menyelamatkan ibu dan janin.

Pada penelitian ini dapat dilihat bahwa hipertensi pada kehamilan sebagian besar kejadian BBLR dialami oleh ibu-ibu dengan tidak memiliki riwayat hipertensi pada kehamilan yaitu sebanyak $72,7 \%$ demikian juga kejadian tidak BBLR banyak dialami oleh iu-ibu dengan riwayat tidak hipertensi yaitu sebanyak 76,9\%. Hasil pengujian statistik didapatkan $\mathrm{p}$ value $=0,792$ artinya $\alpha>0,05$ dengan demikian dapat disimpulkan bahwa tidak ada hubungan antara hipertensi pada kehamilan dengan kejadian BBLR. Dari hasil analisis juga diperoleh OR 1,417 yang artinya ibu-ibu dengan hipertensi pada kehamilan memperoleh peluang sebesar 1,417 kali untuk terjadinya BBLR dibanding dengan ibu-ibu yang tidak mengalami hipertensi kehamilan. Berbeda dengan penelitian yang sudah dilakukan oleh Nurliawati (2015); Wati (2013) dan Sigmawati (2010) yang menyatakan bahwa ada hubungan yang sangat signifikan dari kondisi ibu dengan preeklampsi dan 
ekslampsi terhadap kejadian BBLR dari bayi yang dilahirkan dengan $\mathrm{p}$ value $=0,000$. Hal ini dimungkinkan karena pada penelitian yang dilakukan oleh penulis jumlah sampel kecil untuk sebuah penelitian survey sehingga tidak memperlihatkan data yang refresentatif.

\section{SIMPULAN DAN SARAN}

Berdasarkan hasil penelitian yang dilakukan didapatkan hasil tidak ada hubungan yang bermakna antara hipertensi pada kehamilan dengan kejadian BBLR ( $p$ value $=0,792$ ). Tetapi walaupun demikian, perawat diwajibkan untuk lebih berperan aktif dalam memberikan pendidikan kesehatan bagi para wanita khususnya wanita usia subur untuk dapat lebih menjaga kehamilannya agar kejadian BBLR dapat dikurangi. Bagi penelitian selanjutnya diharapkan jumlah sampel dan cakupan diperluas sehingga jumlah sampel bertamah dan refresentatif untuk sebuah penelitian survey.

\section{DAFTAR PUSTAKA}

Datar, A., \& Jacknowitz, A. (2009). Birth weight effects on children's mental, motor, and physical development: Evidence from Twins Data. Journal of Maternal Child Health, (13), 780-794.

Festy, P. (2013). Analisis faktor resiko pada kejadian BBLR di Kabupaten Sumenep.https://id.scribd.com. Diunduh tanggal 2 September 2013.
Hack, M., Schlucter, M., Cartar, L., RahmanM., Cuttler, L. \& Borawski, E., (2003). Growth of very low weight infants to age 20 years. Journal of Pediatrics, (112), 30-38.

Hastono, S.P. (2007). Analisis data kesehatan. Jakarta: FKM UI.

Hockenberry, M.J., \& Wilson, D. (2009). Wong's essentials of pediatric nursing. ( $8^{\text {th }}$ edition). St. Louis: Elsevier.

Manuaba, I.B.G, 2008. Ilmu Kebidanan, Penyakit Kandungan dan KB. EGC. Jakarta.

Martika, E. (2012). Hubungan BBLR dengan perkembangan motorik pada anak. thesis.umy.ac.id/datapublik/t26273.pdf. Diunduh pada tanggal 2 September 2015.

Nurliawati, E. (2014). Hubungan antara preekslampsi berat dengan bayi berat lahir rendah (BBLR) di RSU Dr. Soekardjo Tasikmalaya. Jurnal Kesehatan Bhakti Tunas Husada. Volume 12 (1).

Pantiawati, I. (2010). Bayi dengan Berat Badan Lahir Rendah. Yogyakarta: Mulia Medika.

Resnick, M.B., Davis, F.E., Nelson, R.M., Eitzman, D.V., \& Bucciarelli, R.L. (1987). Developmental intervention for low birth weight infants: Improved early developmental outcome. Pediatrics. Official Journal of American Academy of Pediatrics. (80). 68-74

Sabri, L., \& Hastono, S.P. (2009). Statistik kesehatan (Edisi Revisi). Jakarta: Rajawali Pers.

Sastroasmoro, S., \& Ismael, S. (2010). Dasar-dasar metodologi penelitian klinis (Edisi ketiga). Jakarta: CV Sagung Seto.

Sigmawati, T. (2010). Hubungan hipertensi pada ibu hamil dengan kejadian BBLR di RSUP Dr. Soeradji Tirtonegoro Klaten Tahun 2010. http://digilib.unisayogya.ac.id/id/eprint/ 3298. Diakses pada 24 Januari 2019. 
JURNAL SEHAT MASADA VOLUME XIII NOMOR 1 Januari 2019 ISSN : 1979-2344

Sulistyorini, D\& Siswoyo, S. (2015). Analisis faktor yang mempengaruhi kejadian BBLR di Puskesmas Perkotaan Kabupaten Banjarnegara. https://id.scribd.com/doc/256540329/a nalisis-bblr-1. Diunduh tanggal 2 September 2015.

Suradi \& Kristina (Ed). 2004. Manajemen Laktasi Cetakan ke 2. Jakarta: Program Manajemen Laktasi Perkumpulan Perinatologi Indonesia.
Trihardiani, I. (2011). Faktor resiko kejadian berat badan lahir rendah di wilayah kerja Puskesmas Singkawang Timur dan Utara Kota Singkawang. eprints.undip.ac.id/32555. Diunduh tanggal 2 September 2015.

Wati, L.K. (2013). Hubungan antara preeklampsi/eklampsi dengan kejadian bayi berat lahir rendah (BBLR) di RSU Dr. Soedarso Pontianak tahun 2012. Jurnal Mahasiswa PSPD FK Universitas Tanjungpura. Volume 3 (1). 